\title{
Tako-Tsubo Cardiomyopathy (Broken-Heart Syndrome)
}

\author{
Marina Souzan* \\ HCA Florida Hospitals, USA
}

Submission: December 21, 2016; Published: January 09, 2017

*Corresponding author: Marina Souzan, HCA Florida Hospitals, 8950 SW 142 Avenue, Apt\#919 Miami, Florida 33186, USA, Email: emailmarinasouzan@gmail.com

\section{Introduction}

In Japan as recently as 1991 TakoTsubo recognized as a syndrome, the physicians noted the characteristic changes in Left Ventricular apical ballooning similar to an octopus trap. Tako meaning Octopus and Tsubo meaning Japanese trap pot. It is also sinuously known as apical ballooning syndrome, acute stress-induced cardiomyopathy or commonly as broken heart syndrome (Figure 1).

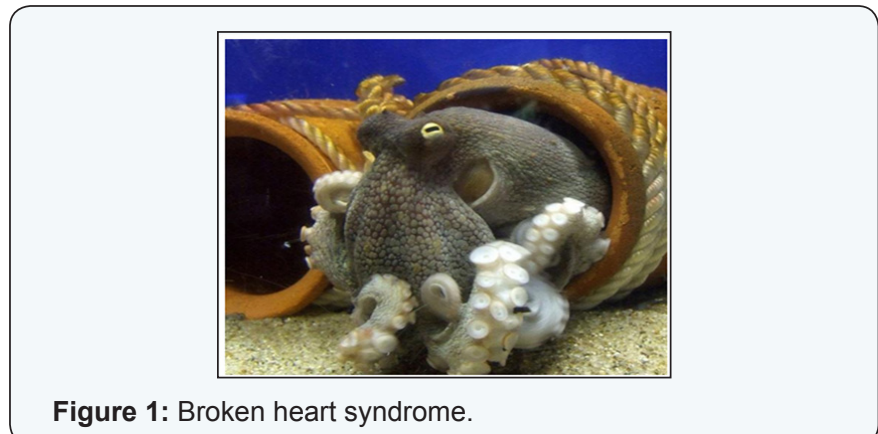

\section{Etiology}

Caused by sudden surging stress hormones catecholamines (are epinephrine (adrenaline), nor-epinephrine (noradrenaline), and dopamine). Release of the hormones epinephrine and nor-epinephrine from the adrenal medulla of the adrenal glands is part of the fight-or-flight response for example, adrenaline essentially "stuns" or contracts the heart, triggering changes in heart muscle cells or coronary blood vessels (or both) that prevent the left ventricle from pumping effectively.

Women have estrogen receptors all over their autosomal (body) cells whether it's brain heart other organs. These estrogen receptors have special effect on smooth muscles by keeping them relaxed. When women reach menopause this protective effect is lost. This could be one of the possible causes why women suffer more from Broken heart syndrome and
Prinzementals angina both etiology being vaso spastic vessels/ Ventricular myocardium (Figure 2).

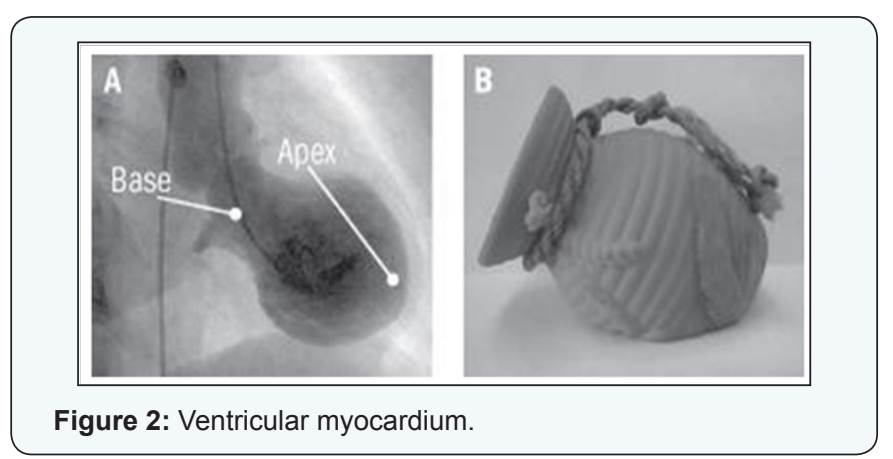

Features of Takotsubo cardiomyopathy (Figure 3)

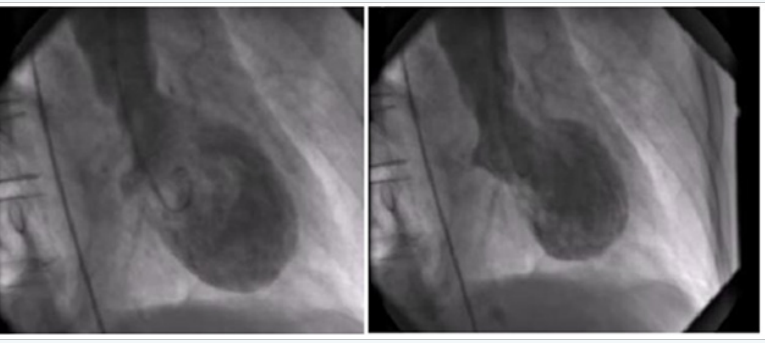

Figure 3: Features of Takotsubo cardiomyopathy.

a) Shortness of breath after severe stress (emotional or physical)

b) Electrocardiogram abnormalities that mimic those of a heart attack

c) No evidence of coronary artery obstruction in diagnostic catheterization

d) Movement abnormalities in the left ventricle (low EF $\%)$

e) Ballooning of the left ventricle (Apical Ballooning) 
f) Recovery within a month

g) Chest pain, dyspnea, and syncope

h) Stressors associated with Takotsubo cardiomyopathy

i) Sudden drop in blood pressure

j) Serious illness, surgery, or medical procedure (e.g., cardiac stress test)

k) Severe pain

l) Domestic violence

m) Asthma attack

n) Receiving bad news (such as death of all family members)

o) Car or other accident

p) Unexpected loss of emotionally valued person or material loss , illness, or injury of a close relative, friend, or pet

q) Fierce argument(Employer argument)

r) Financial loss

s) Intense fear

t) Public speaking

u) A surprise good or bad or other sudden surprise

v) Drug addicts.

w) Pre existing psychiatric history or disorder.

x) Genetic predisposition.

\section{Cardiac Catheterization in CathLab (Figure 4)}

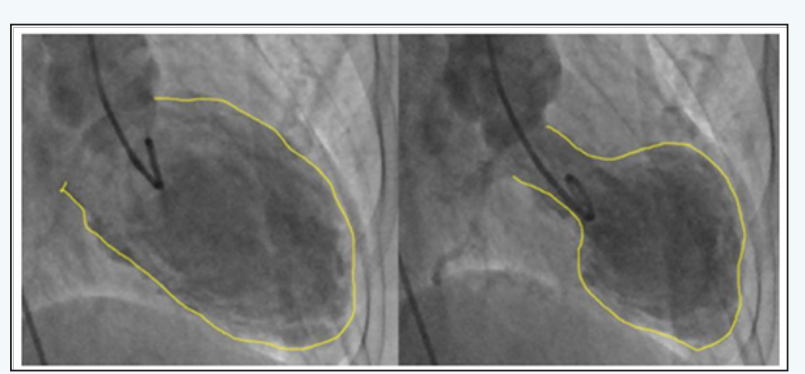

Figure 4: Left Ventriculogram Angiography.

These patients mostly end up on Cathlab table for diagnostics for Left heart Catheterization. The usual findings are clear right and left coronaries but compromised left ventricular Ejection Fraction and obstructive Left Ventricular Outflow Tract Obstruction. Right Ventricle is also assumed to be equally affected however, it is anatomically impossible to be angiogram.

When myocardium is stunned or extremely contracted like in restrictive disease the intra myocardial blood vessels become squeezed supply to deeper tissues and there are assumptions made that chordate tendinea are stressed due to excessively pulling get fatigued and broken hence the ischemic release of Cardiac enzymes. Serum cardiac troponin levels are elevated in most patients with stress cardiomyopathy.

Creatine kinase levels are generally normal or mildly elevated. Brain natriuretic peptide (BNP) or N-terminal pro-BNP levels are low level rise due to severity of LV dysfunction. ECG Rhythm Abnormalities: Evolutionary T wave changes, new Q wave prolonged QTc similar to MI.

Research: Echocardiography: Identification of wall motion abnormalities - LV dysfunction is identified by echocardiography or left ventriculography, which reveals regional wall motion abnormalities (hypo kinesis, akinesis, or dyskinesis) in one of the characteristic patterns However Echocardiography is not a diagnostic but only a study tool.

I. Apical type - In the typical form of this disorder, there is systolic apical ballooning of the LV, reflecting depressed mid and apical segments, and there is hyper kinesis of the basal walls. Less common (atypical) variants:

II. Mid-ventricular type - In the second most common type, ventricular hypo kinesis is restricted to the mid-ventricle with relative sparing of the apex.

III. Basal type - Hypokinesis of the base with sparing of the mid-ventricle and apex (reverse or inverted Takotsubo

IV. Focal type - A rare focal variant is characterized by dysfunction of an isolated segment (most commonly the anterolateral segment) of the LV.

Management: There are no evidence-based guidelines for treating Takotsubo cardiomyopathy. Clinicians usually recommend standard heart failure medications such as beta blockers, ACE inhibitors, and diuretics (water pills). They may give aspirin to patients who also have atherosclerosis (plaque buildup in the arterial walls). Although there's little evidence on long-term therapy, beta blockers (or combined alpha and beta blockers) may be continued indefinitely to help prevent recurrence by reducing the effects of adrenaline and other stress hormones.

Supportive therapies have been with insertion of IABP insertion, medically pressers, Ionotrpoes supportive circulation, haemodynamically supportive IABP Intra Aortic Balloon Pump, ECMO Extracorporeal membrane oxygenation (ECMO), known as extracorporeal life support (ECLS) in some rare cases. It's also important to alleviate any physical or emotional stress that may have played a role in wall movement clear up in one to four weeks, and most patients recover fully within two months. 95\% of the patients will have complete resolution.

\section{Complications}

Death is rare, but heart failure occurs in about $20 \%$ of patients. Apical rupture, thrombus formation may increase 
mortality. Highly recommended to get an expert Psychiatric consultation for patients especially for those with a known history of mental (psychiatric) and Neurological preexisting problems to be treated alongside with the cardiac management.

\begin{tabular}{l} 
Your next submission with Juniper Publishers \\
will reach you the below assets \\
- Quality Editorial service \\
- Swift Peer Review \\
- Reprints availability \\
- E-prints Service \\
- Manuscript Podcast for convenient understanding \\
- Global attainment for your research \\
- Manuscript accessibility in different formats \\
( Pdf, E-pub, Full Text, audio) \\
- Unceasing customer service \\
Track the below URL for one-step submission \\
https://juniperpublishers.com/online-submission.php \\
\hline
\end{tabular}

